As implicações da representação da violência na literatura e no cinema:

Cidade de Deus | 195

\title{
AS IMPLICAÇÕES DA REPRESENTAÇÃO DA VIOLÊNCIA NA LITERATURA E NO CINEMA: CIDADE DE DEUS
}

Eliane Dutra ${ }^{55}$

Resumo: O objeto deste estudo consiste em analisar a obra literária Cidade de Deus (1997) escrita por Paulo Lins e, sua respectiva releitura cinematográfica de título homônimo dirigido pelo cineasta Fernando Meireles, em 2002. Pretende-se refletir a influência que Cidade de Deus, principalmente, a produção cinematográfica, teve em relação ao grupo de pessoas por ela representadas. No caso de Cidade de Deus, a comunidade sofreu preconceito quanto a sua imagem veiculada, que pode diferir muito da realidade vivenciada pelos habitantes daquela região. Segundo Paulo Lins, a trama narrada está repleta de acontecimentos que condizem com a realidade da comunidade, onde ele morou cerca de 30 anos, sendo que; por essa mesma razão possui suma importância ao passo que transformar-se-ia numa forma de denúncia e de possível intervenção social. $\mathrm{O}$ trabalho conta com um levantamento bibliográfico e também com uma pesquisa de dados secundários (dados já existentes em diversas fontes, como sites na internet, jornais, revistas, fontes governamentais e judiciais), para que se possa entender sobre o impacto de Cidade de Deus.

Palavras-chave: Violência; Cidade de Deus; representação; implicações.

Abstract: The objective of this study is to analyze the literary work of the City of God (1997) written by Paulo E. Lins, its respective cinematic rereading of homonymous title directed by filmmaker Fernando Meireles in 2002. It is intended to reflect the influence that the City of God, mainly the film production, had in relation to the group of people represented by it. In the case of the City of God, the community itself was prejudiced as to its conveyed image, which can greatly differ from the reality experienced by the inhabitants of that region. According to Paulo E. Lins, the narrated plot is filled with events that match the reality of the community, where he has lived for about 30 years, and for that reason it is very important while it would become a form of denunciation and possible social intervention. The work has a bibliographic survey also with a survey

55 Doutoranda em Literatura do programa de Pós-graduação em Literatura da Universidade Federal de Santa Catarina- UFSC 
of secondary data (already existing data in various sources, such as Internet sites, newspapers, journals, governmental and judicial sources), so that can be understood about the City of God work impact.

Key words: Violence; City of God; representation; implications.

Muitas são as obras literárias (brasileiras e estrangeiras) e adaptações fílmicas que nos levam a refletir sobre os temas como violência, crimes e miséria. Eles são conteúdos usados como matériaprima para produções literárias, cinematográficas que, muitas vezes, resultam em grande polêmica entre produtores e críticos. Esses temas, e principalmente, a violência não é algo novo na literatura brasileira, pois o uso dessa temática pode ter raízes antigas. Desse modo, atrevemo-nos a dizer que boa parte da história de nossa literatura poderia ser narrada a partir de suas relações com a violência.

No Brasil, filmes sobre crimes, violência obtiveram grande sucesso, desde as primeiras décadas do século XX. E, uma das obras de repercussão no século XXI, devido seu conteúdo ser sobre violência, criminalidade, miséria é Cidade de Deus (tanto o livro como adaptação fílmica). Cidade de Deus é o livro de Paulo Lins, lançado em 1997, após ele foi adaptado para o cinema por Fernando Meireles, em 2002. A adaptação foi sucesso no exterior, com um público de, aproximadamente, 3,2 milhões de espectadores, sendo que recebeu quatro indicações ao Oscar.

Cidade de Deus é uma escrita sobre marginalizados, pobres e o tráfico de drogas. Apresenta a violência policial e familiar, a falta de auxílio das políticas públicas, a rotina das camadas menos favorecidas do bairro Cidade de Deus, entre as décadas de 1960 a 1980. Cidade de Deus é tema de muitas produções acadêmicas, objeto de diversas pesquisas em diferentes áreas do conhecimento, devido à sua estreita ligação com a realidade social de algumas comunidades pobres, marginalizadas do Rio de Janeiro.

O livro é resultado de uma pesquisa ampla e relevante, antes de ser publicado pela Editora Companhia das Letras, em 1997, era o objeto de estudo da dissertação de mestrado de Paulo Lins. Ao tomar a forma de livro, Cidade de Deus, Paulo Lins classifica-o como "romance", porém, baseado em fatos e personagens reais. Dessa forma, este artigo tem por objetivo verificar as implicações, influências na vida daqueles que, Cidade de Deus, principalmente, o filme, se refere. Por conseguinte, objetiva-se, 
As implicações da representação da violência na literatura e no cinema: Cidade de Deus | 197

refletir sobre o papel da literatura e do cinema enquanto agentes de reflexão sobre a sociedade.

\section{Cidade de Deus: implicações e influências}

Em 2002, Cidade de Deus foi adaptado para o cinema pelo cineasta, Fernando Meirelles. O filme recebeu críticas e aplausos, sendo que milhões de pessoas foram às salas de cinema prestigiar o filme. Ele ganhou 4 indicações ao Oscar, todas as categorias nobres. Foi vendido para quase todos os mercados internacionais. O elenco é formado por poucos atores profissionais, a grande maioria, são jovens oriundos de comunidades pobres, pessoas acostumadas com a linguagem, a lógica, a vida em locais como os apresentados na tela.

O filme segundo Ivana Bentes (1997), organizadora do livro Cartas ao mundo/Glauber Rocha, mobilizou colunistas e críticos bissextos. Formaram-se logo facções rivais: uma de detratores, escorados no conceito "cosmética da fome"; outra defendeu o filme, apontou como uma denuncia social, sendo que esse filme não é apenas um filme de entretenimento, mas "[...] um fato importante, um acontecimento crucial, um furo na consciência nacional. Cidade de Deus não é um retrato condoído das favelas; não tem um só traço de sentimentalismo. Ele é também o nosso retrato, a 24 quadros por segundo [...]" (JABOR, 2002, 01).

O professor e jornalista Zenuir Ventura (2002, p.01) aponta que: “[...] assistir Cidade de Deus é um dever cívico [...]". Ele mencionou ainda que o filme não apresenta problemas, o roteiro é envolvente, a montagem e a fotografia mudam de acordo com a narrativa. Os atores conseguem um efeito realístico em suas representações. Cidade de Deus não serve só para entreter, não podemos comparar apenas uma diversão, um James Bond ou algo do tipo.

Em Cidade de Deus, encontra-se, segundo Paulo Lins (2003), pautas, reflexões de sua vida, sendo relatos de um olhar de dentro, de alguém, que não apenas pesquisou para construção de um livro, mas que viveu a favela ${ }^{56}$ e toda a sua desventura. Para Roberto Schwarz (1999, p.

\footnotetext{
${ }^{56}$ Favela (Fava + ela), do Morro da Favela (RJ), assim denominado pelos soldados que ali se estabeleceram ao regressar da campanha de Canudos. E logo: S.f. Conjunto de habitações populares toscamente construídas (por via de regra em
} 
168), um dos principais críticos do nosso país, é uma obra que, “[...] merece ser saudada como um acontecimento. $O$ interesse explosivo do assunto, o tamanho da empresa, a sua dificuldade, o ponto de vista interno e diferente, tudo contribui para a aventura artística fora do comum".

Paulo Lins, em uma entrevista para Paiol Literário ${ }^{57}$, em 2013, relatou que se sente marcado pelo lançamento do livro e, escrever, Cidade de Deus, foi um acerto de contas com a sua realidade. "Eu era muito revoltado. Com a vida, com a política brasileira, com a escravidão, com a colonização. Só não fui mais revoltado com os portugueses porque meus avós eram portugueses".

As palavras, e a literatura foram meios, para escancarar sua insatisfação com a realidade, a qual pertencia Paulo Lins. Cidade de Deus é considerada uma das maiores obras da literatura brasileira contemporânea. Paulo Lins transpôs para o mundo literário uma situação social arruinada, falida, realista ligando em sua narrativa a agilidade da ação cinematográfica e o lirismo da poesia, levou sua escrita ao extremo, conquistou leitores, movimentou a crítica literária e cinematográfica do século XX e XXI.

Cidade de Deus dividiu a crítica, fez os moradores da comunidade Cidade de Deus falar, seduziu leitores e espectadores, levou milhões de pessoas as salas de cinema com força e capacidade de propiciar imaginações e reflexões sobre diálogos nos mais diversos âmbitos. Duas obras artísticas que discutem a violência, cada uma com suas artimanhas, técnicas, e o que se percebe é que, entre as telas do cinema e as páginas dos livros há laços estreitos, pois as palavras tem a capacidade de acionar nossos sentidos e se transformar em imagens em nossa mente. Ocorre é que, tanto o cinema como a literatura nos levam a reflexão, a indagação e de uma forma que uma linguagem complementa e amplia o poder de atuação da outra.

A adaptação (do livro para filme) levou ao limite da perfeição alguns elementos fotográficos e técnicas de linguagem. Cidade de Deus contribuiu também para o cinema brasileiro a inserir-se mais uma vez no circuito internacional: "Cidade de Deus alcançou um efeito tremendo não

morros) e com recursos higiênicos diferentes (também convida a conferir ou confrontar o termo "barraco de lata) (Dicionário Aurélio, 2008 p. 879).

${ }^{57}$ Paiol Literário é um projeto promovido pelo jornal Rascunho em parceria com a Prefeitura de Curitiba e a Fundação Paulo Lins. Paiol Literário. Disponível em: <http://rascunho.gazetadopovo.com.br/paulo-lins/->. Acesso em: 06 jan. 2018. 
As implicações da representação da violência na literatura e no cinema: Cidade de Deus | 199

apenas para o Brasil, mas para qualquer filme que não seja falado em inglês" (BOSCOV, 2004, p. 80). No entanto, infelizmente, Fernando Meirelles não pode festejar como merecia essa conquista, pois seu filme já estreou cercado por polêmica. Nenhum filme da retomada do cinema brasileiro suscitou tamanha polêmica quanto Cidade de Deus, expõe Isabela Boscov (2004).

Cinema da retomada não é um movimento estético e sim, a volta da produção cinematográfica brasileira, em 1993, interrompida até então, aponta Sérgio Rizzo (2003). Os produtores de cinema, brasileiros, nos anos 1970 e 1980 passaram por muitas dificuldades, poucos eram profissionais que conseguiam fazer filmes, devido à falta de incentivo. E, foi em 1990, destaca Sato (2009), com o fim da Embrafilme ${ }^{58}$ pelo governo de Fernando Collor de Mello, que ocorreu o ápice da crise de produção de filmes.

Incentivos para desenvolvimento da sétima arte voltou acontecer em 1993, quando foi criada a Lei do Audiovisual, que impulsionava novos investimentos por parte do governo federal e, então, deu-se início a que chamamos de cinema da retomada. Nessa época, o cinema transformou-se, cineastas, produtores não ficavam mais presos a gêneros ou temáticas específicas, podiam optar por diferentes assuntos, tais como: política, comédias, denúncia, entretenimento, policias, épicos e infantis. Os profissionais tinham também a disposição novos aparatos tecnológicos, que tornaram mais fácil e viável a execução cinematográfica no Brasil ${ }^{59}$.

[...] cinema da retomada, é um cinema voltado para a indústria, voltado para o mercado, com temas brasileiros tratados de modo internacional. Acabou o som vagabundo, acabou o enquadramento qualquer, acabou a câmera qualquer, tem-se uma equipe super e nessa equipe super, o fotógrafo ganhou um papel de destaque total, o fotógrafo

58 Embrafilme foi uma empresa estatal brasileira produtora e distribuidora de filmes cinematográficos. Foi criada através do decreto-lei № 862, de 12 de setembro de 1969, como Empresa Brasileira de Filmes Sociedade Anônima. Disponível em: 〈http://ctav.gov.br/2008/10/10/a-embrafilme/〉. Acesso em 10/02/2018.

59 <http://cinemaemcena.cartacapital.com.br/coluna/ler/764/n\%C3\%A3o-gostade-filme-nacional-entenda-o-cinema-da-retomada $>$. Acesso em 10/01/2018. 
agora é quase que o rei do filme (LYRA 2002, apud VASCONCELOS; MATOS, 2012, p. 122).

O cinema da retomada apresentava bom acabamento técnico e mais qualidade no som, e na imagem. Importante ressaltar ainda que, houve oportunidade para uma nova geração de profissionais, cineastas pudessem se revelar, o que permitiu maior heterogeneidade ao cinema realizado no Brasil ${ }^{60}$. Após dois anos, da nova Lei do Audiovisual, surgiram as primeiras produções nacionais de importância. $O$ primeiro filme, importante, foi à produção de Carlota Joaquina, A Princesa do Brasil (1995), de Carla Camurati. De Carlota Joaquina até a atualidade o cinema brasileiro, apesar de ainda enfrentar certas dificuldades de distribuição, divulgação e exibição, voltou a conquistar o público, indicações ao Oscar, prêmios nacionais e internacionais.

A primeira indicação ao Oscar de melhor filme estrangeiro foi $\mathrm{O}$ Quatrilho em 1995; o segundo em 1997, O que é Isso, Companheiro?; o terceiro 1998, Central do Brasil - ganhou o Urso de Ouro e Globo de Ouro de Melhor Filme Estrangeiro, foi também candidato ao Oscar de Melhor Filme de Língua Estrangeira. A quarta indicação ocorreu com Cidade de Deus, em 2002.

Cidade de Deus para alguns autores, crítico de cinema, como Luiz Zanin Oricchio (2003), é um marco para o cinema brasileiro. Para ele, também o ciclo da produção da retomada foi finalizado com o filme Cidade de Deus (2002), "[...] que teria funcionado como uma espécie sintetizador de uma tendência que se desenhou ao longo dos anos 90, e, por isso mesmo, poderia ser considerado como um divisor de águas na história recente do cinema nacional" ${ }^{\prime 1}$.

Na análise de Luiz Zanin Oricchio (2003), Cidade de Deus é um bom filme de entretenimento. A influência do cineasta americano Quentin Tarantino é percebível em Cidade de Deus. Meirelles não poupou esforços para apresentar com perfeição alguns elementos e técnicas de linguagem que proporcionam grande prazer ao espectador, ao mesmo tempo em que o colocam diante de doses consideráveis de violência que existe nos filmes de Quentin Tarantino. Em Cidade de Deus "[...] predomina a forma da violência espetacularizada, isto é, neutralizada. O

${ }^{60}$ Idem.

${ }^{61}<\mathrm{http}: / /$ cinemaemcena.cartacapital.com.br/coluna/ler/764/n\%C3\%A3o-gostade-filme-nacional-entenda-o-cinema-da-retomada $>$. Acesso em 10/01/2018. 
As implicações da representação da violência na literatura e no cinema:

Cidade de Deus | 201

morticínio, que vai se tornando crescente à medida que a história avança, termina por embrutecer o espectador, que não sofre ou não se choca com o que vê na tela" (ORICCHIO, 2003, p.158).

Nessa esteira, Ely Azeredo, crítico de cinema, ressalta sobre a espetacularização da violência no filme apontando que, estamos vivendo em tempo de política-espetáculo, mídia-espetáculo, até de religiosidadeespetáculo. "Porque um cineasta estaria obrigado a abordar o tema de sua escolha segundo cânones do cinema-vérité (ou cinema direto), do ensaísmo antropológico ou do documentarismo engajado?" (AZEREDO, 2002, p. $1)$.

Quanto à comunidade Cidade de Deus foram pouquíssimas pessoas que leram o livro, mas o filme todo mundo viu relata Renato Oliveira Rocha (2014). Foi através da adaptação fílmica, indicação ao Oscar, que muitas pessoas tiveram conhecimento da obra literária. O livro não tem o mesmo encanto, charme do filme homônimo, nem a mesma energia espetacular e capacidade de identificação.

Quando o filme estourou no cenário internacional, foi parcialmente aceito pela comunidade Cidade de Deus. Paulo Lins passou a ser malvisto na comunidade em que cresceu, moradores reclamaram da imagem negativa sobre Cidade de Deus que o livro passa. Que só tem bandido, violência etc. Mas outra parte adorou. "[...] Entendeu que o livro é ficção, é literatura. Que isso deu um filme e não um documentário [...]" (LINS, 2012, p. 01).

Moradores há mais de 20 anos na comunidade apontam que há muitos equívocos no filme, com as cenas de maior impacto de violência, não condizem com a verdade. E, que um erro gravíssimo cometido por Paulo Lins, foi colocar em seu livro, os nomes reais das pessoas "[...] que tiveram atribuídas a suas trajetórias ações e até crimes que não teriam cometidos, como o aliciamento de menores para o tráfico".

Para Fernanda Mena (2003, p. 1), jornalista da Folha de São Paulo, o lançamento do filme, Cidade de Deus, aumentou o preconceito também de policias e a diminuição de oportunidades de trabalho.

"Esculacharam a favela!", disse à reportagem da Folha um comerciante de 45 anos, que preferiu não se identificar. "Depois disso aí, quando souberam que eu era da Cidade de Deus, ficou mais difícil abrir um crediário". "Tem casos de meninos aqui que foram procurar emprego e, quando leram no currículo o endereço onde moravam, disseram 
apenas que iriam enviar uma carta com o resultado da seleção. Os meninos estão esperando essas cartas até hoje. E elas nunca vão chegar", conta o líder comunitário Jorge Vilela, 42, que desde 1971 vive na CDD -como os moradores chamam a favela. Para estudante Paulo (nome fictício), 19, o pior foi a mudança da abordagem policial com os moradores. "A gente já não era tratado pela polícia de uma maneira legal. Parece que piorou ainda mais. Agora, eles acham que todo mundo aqui é bandido, traficante ou está envolvido com o tráfico." Ao focar o enredo do filme nos traficantes e bandidos da CDD, o filme, de acordo com os moradores, generalizou o banditismo.

Fernando Meirelles, ao apresentar os problemas da comunidade Cidade de Deus - a violência, a guerra travada pelo tráfico de drogas acabou, pelo que parece, prejudicando aqueles que são vítimas de tal situação. As condições de vida dos moradores pioraram. José Neves, 75, presidente da União Comunitária da Cidade de Deus, morador, há mais de 30 anos na comunidade, ressalta que o filme "[...] desmoralizou a comunidade e marginalizou seus moradores ao mostrar uma situação que não corresponde à realidade atual da CDD [...]" (Neves apud Mena, 2003, p. 01).

Moradores, adolescentes, da comunidade, embora seduzidos pelo filme, segundo Fernanda Mena (2003, p.1), dizem que o filme é interessante, mas não é a verdade sobre a comunidade, e comentam na entrevista: "[...] Agora, meus colegas da escola acham que aqui é barrapesada, que todo mundo rouba, que isso, que aquilo. Tudo por causa das coisas que aparecem no filme. E disso eu não gostei, não".

Segundo Maria Fernanda Erdelyi (2005, p. 01), Paulo Lins, Fernando Meirelles e a editora Companhia das Letras responderam a processos. Os moradores Benite Correa, Sebastiana Silva e Ailton Costa Bittencourt, processaram Paulo Lins, alegando identificação com os personagens do livro. Os moradores reclamam por não terem sido consultadas na publicação e veiculação de suas vidas. Acionaram também a editora Companhia das Letras, que editou a obra, reivindicando danos morais e materiais, apontando ofensa à honra e ao direito de intimidade.

Ailton Costa Bittencourt, mais conhecido como Ailton Batata ressalta que o personagem Sandro Cenoura inventado por Paulo Lins era ele mesmo. Ailton Batata processou também os produtores do filme, 
As implicações da representação da violência na literatura e no cinema: Cidade de Deus | 203

Cidade de Deus. A editora respondeu a mais três ações que tramitaram na Justiça. Sebastiana Silva, moveu ação contra Paulo Lins, alegando ser a personagem Dona Ba. Sebastiana diz que no livro de Lins tem nove páginas dizendo que Ba era prostituta e dona de um bordel. "Conforme ela, na vida real, não é prostituta nem dona de bordel” (ERDELYI, 2005, p. 01).

Benite Correa, que processou também Paulo Lins, falou ser o personagem Benite. Ela diz que, o livro cita o personagem Bené, que seria seu irmão Benedito. Anita de Souza, mãe de Benite e de Benedito processou a editora e Lins alegando que seria mãe do personagem Bené, e que estavam falando de seu filho sem sua autorização (ERDELYI, 2005, p. 01).

Moradores que entraram na Justiça ressaltam que o livro e o filme, criaram uma imagem muito negativa da comunidade Cidade de Deus, dando a impressão de que lá só moram bandidos, ladrões e marginais. “[...] Alegam que por causa desta má fama, segundo eles criada pela ficção e sem referência na vida real, não conseguem emprego e passaram a ser ainda mais discriminados [...]" (ERDELYI, 2005, p.01). As obras artísticas, rederam sucesso, prestigio a Fernando Meirelles e Paulo Lins, mas a conforme relatos dos moradores da comunidade, nenhum beneficio ocorreu após o lançamento das obras, somente aumentou as dificuldades de sobrevivência.

Em defesa, o cineasta Fernando Meirelles, disse que “(...) a gente não inventou aquela história. É como um espelho: a culpa não é do reflexo, é da realidade que está sendo refletida" (MORETZ-SOHN, 2002, p.3). Paulo Lins também se posicionou em defesa do filme, ressaltando que não ocorreu um aumento do estigma em relação aos moradores da comunidade Cidade de Deus, visto que este processo “(...) não irá ultrapassar ao que já existe. Todo favelado já é estigmatizado. E complementa: "Omitir o lado ruim é mostrar uma realidade falsa. Mostrei o que eu vivi. Eu passei por tudo aquilo (...)” (apud Globo Barra, 2002, p.01).

Aqui lembremos-nos do que nos diz Roberto Schwarz (1983), que a representação da realidade na literatura (podemos ampliar para obras cinematográficas, principalmente as adaptações literárias), é cabível e importante. $\mathrm{O}$ mesmo autor afirma que a literatura representa uma realidade social. Em sua coletânea, Os pobres na literatura brasileira, tentou demonstrar como a miséria, a pobreza definir-se-iam e estariam representadas nas letras brasileiras. $\mathrm{Na}$ apresentação da obra, ele indica 
que: "[...] basta não confundir poesia e obra de ciência, e não ser pedante, para dar-se conta do óbvio: que poetas sabem muito sobre muita coisa, inclusive, por exemplo, sobre a pobreza [...]" (SCHWARZ, 1983, p. 7). Roberto Schwarz aponta ainda a importância dos estudos literários em cotejo com os estudos cinematográficos para a possível conscientização de um público interessado e que, a partir disso, possam refletir e transformar sua ação social.

Os meios de comunicação de massa, o qual o cinema também está inserido, tem um papel fundamental na organização e no desenvolvimento de determinada realidade social, eles tanto reproduzem quanto modificam a realidade. E, o cinema, mais que outras artes, devido sua técnica, a impressão da realidade, prende a atenção do ser humano e estabelece um vinculo com o imaginário, afirma Metz (1997, p. 16).

[...] Desencadeia no espectador o processo ao mesmo tempo perceptivo e afetivo de "participação" (não nos entediamos quase nunca no cinema), conquista de imediato uma espécie de credibilidade - não total, é claro, mas mais forte do que em outras áreas, às vezes muito viva no absoluto -, encontra o meio de se dirigir à gente no tom da evidencia, como que usando o convincente "É assim", alcança sem dificuldades um tipo de enunciado que o linguista qualifica de plenamente afirmativo e que, além do mais, consegue ser levado em geral a sério.

Não por acaso o cinema conquistou multidões desde seu nascimento. Conquistou também a indústria, o que é fundamental para o cinema. Ele fortaleceu os efeitos da literatura na construção do imaginário coletivo do século XX e, representou para o século XX o que a ficção literária representou para o século XIX, devido seus efeitos tecnológicos que seduzem, hipnotizam as pessoas.

Conforme André Bazin (1991), o cinema conseguiu "fomentar a popularidade da arte no século XX", o que nenhum desenvolvimento artístico conseguiu ao longo da história moderna, pois o romance nos séculos XVIII e XIX era hábito, principalmente, da classe burguesa. Ao contrário, no século XX, o cinema atingiu grande parte da população. "[...] No século XX, nem todos podem ter acesso aos grandes escritores, porém quem é que deixa de ver Carlitos?” (BRITO, 2006, p. 148).

Para Walter Benjamin (1985), o cinema produz um efeito que não era mais sentido com a arte em outros suportes como a obra literária, o 
As implicações da representação da violência na literatura e no cinema: Cidade de Deus | 205

teatro, a pintura. É possível que esse efeito seja ampliado devido aos recursos técnicos de som, imagem e luz de forma que o público se sente mais envolvido na narrativa que lhe é apresentada. A sétima arte é representativa, proporciona ideias e significados mediados por imagens que representam e referem mensagens ideológicas. E, cinema não reflete nem mesmo registra a realidade como qualquer outro meio de representação:

[...] o cinema constrói e "re-apresenta" seus quadros da realidade por meio dos códigos, convenções, mitos e ideologias de sua cultura, bem como mediante práticas significadoras específicas desse meio de comunicação. Assim como o cinema atua sobre os sistemas de significado da cultura - para renová-los, reproduzi-los ou analisá-los -, também é produzido por esses sistemas de significado. O cineasta, como o romancista ou o contador de história, é um bricoleur - uma espécie de faz-tudo que realiza o melhor que pode com o material que tem à mão. $\mathrm{O}$ cineasta usa os repertórios e convenções representacionais disponíveis na cultura a fim de fazer algo diferente, mas familiar; novo, mas genérico; individual, mas representativo (TUNER, 1997, p. 129).

Como aponta Turner (1997), fazer cinema é ligar-se com a cultura, a ideologia, a sociedade etc. E, da mesma forma que o cinema fornece novos significados para a cultura, ele também é produzido, renovado por esses sistemas de significados. Assim sendo, o cinema é uma arte que pode nos ajudar a despertar para reflexão e motivarmos a novas buscas de significação.

Cidade de Deus é um exemplo que podemos citar sobre uma arte, tanto literária como cinematográfica, que dialoga com a sociedade, nos faz pensar e refletir. Cidade de Deus que dividiu a crítica, brasileira, fez os moradores da comunidade Cidade de Deus falar, seduziu leitores e espectadores, levou milhões de pessoas as salas de cinema com força e capacidade de propiciar imaginações e reflexões sobre diálogos nos mais diversos âmbitos.

O livro e o filme, Cidade de Deus, são obras artísticas que discutem a violência, cada uma com suas artimanhas, técnicas, e o que se percebe é que, entre as telas do cinema e as páginas dos livros há laços estreitos, pois 
as palavras tem a capacidade de acionar nossos sentidos e se transformar em imagens em nossa mente. Ocorre é que, tanto o cinema como a literatura nos levam a reflexão e a indagação de uma forma que uma linguagem complementa e amplia o poder de atuação da outra.

Cabe ressaltar que ao analisar, refletir sobre literatura e cinema precisamos lembrar que não há uma única maneira de olhar, interpretar, uma obra nos falará o quanto quisermos percorrer para saber sobre ela, tudo dependerá da disposição de quem analisa. A literatura pode estar muito além de meramente apontar, descrever ou ainda documentar determinada época, ela é capaz nos proporcionar estudos mais aprofundados das questões sociais, políticas e culturais. Pode nos ajudar a refletir sobre representações da vida social e política da mesma época ou de épocas diferentes (mesmo século ou séculos diferentes); dialogar ou identificar, desordens e formas de resistência de minorias sociais e políticas.

O romance, Cidade de Deus, descreve, documenta, denuncia e expõe a vida de pessoas que sofrem violência e também dos que se tornaram violentos. Sua narrativa dialoga com a sociedade, ajuda-nos a refletir sobre a vida, a política, a miséria, é uma obra que abre espaço para pesquisas, indagações e estudos. Lembremos-nos aqui apontamentos de Antoine Compagnon (2009, p 60) de que: “[...] Literatura deve ser estudada porque oferece um meio - alguns dirão até mesmo o único - de preservar e transmitir a experiência dos outros, aqueles que estão distantes de nós no espaço o e no tempo, ou que diferem de nós por suas condições de vida".

Cidade de Deus é um exemplo do entrelaçamento entre narrativa literária com o contexto social e permite uma análise, por exemplo, como o espaço construído no texto é elemento propulsor para se refletir sobre violência, miséria, injustiça social, enfim, os menos favorecidos na sociedade brasileira. Nessa perspectiva, podemos retomar os autores Austin Warren e René Wellek, (2003, p.34), que apontam que a literatura pode apresentar normas, articulações que fazem parte do contexto da sociedade, "[...] a literatura é uma instituição social que utiliza, como meio de expressão específico, a linguagem - que é criação do social".

No entanto, cabe ressaltar que Wellek e Warren (2003, 114), não julgam que literatura é um espelho que reproduz por concreto a realidade, a situação social, seria um equívoco pensar dessa forma, pois "[...] um escritor não deixa de explanar a sua experiência e sua concepção total de vida, mas seria manifestadamente falso dizer que ele exprime a 
As implicações da representação da violência na literatura e no cinema: Cidade de Deus | 207

vida total - ou até mesmo a vida total de uma época - de forma complexa e exaustiva [...]".

Os autores questionam ainda até que ponto a literatura é determinada realmente pelo ambiente social que representa. Levantam também considerações teóricas levando em conta a condição social do escritor, a origem do escritor, embora isso não seja (sempre) tão relevante, pois segundo eles, escritores, frequentemente, se colocam a serviço de outra classe. Ilustram o fato dizendo que a "[...] maior parte da poesia palaciana foi escrita por homens que, embora nascidos de condições mais baixas, adotaram a ideologia e o gosto dos seus patronos [...]" (WARREN; WELLEK, 2003, p. 121). Em linhas gerais, Austin Warren e René Wellek mencionam que os escritores certamente influenciam e são influenciados pela sociedade, mas sua origem social não implica necessariamente, uma fidelidade ideológica a tal origem.

A literatura dialoga com a realidade, mas, a realidade é recriada e, assim, dispõem de outros sentidos, os quais independem do artista e da experiência do contexto de onde surgiu. $\mathrm{O}$ autor constrói ideias, verdades que nem sempre são claras, objetivas tais como de sua vivência, e então literatura é parte da vida, mas não a realidade concreta, defende Afrânio Coutinho (1950, p. 62).

[...] é uma transfiguração do real, é a realidade recriada através do espírito do artista e retransmitida através da língua para as formas, que são os gêneros, e com os quais ela toma corpo e nova realidade. Passa, então, a viver outra vida, autônoma, independente do autor e da experiência de realidade de onde proveio. Os fatos que lhe deram às vezes origem perderam a realidade primitiva e adquiriram outras, graças à imaginação do artista. São agora fatos de outra natureza, diferentes dos fatos naturais objetivados pela ciência ou pelo social. $\mathrm{O}$ artista literário cria ou recria um mundo de verdades que não são mensuráveis pelos mesmos padrões das verdades factuais. Os fatos que manipula não têm comparação com os da realidade concreta (COUTINHO, 1950, p. 62).

Nessa mesma linha de pensamento é que se insere Terry Eagleton, ao se referir a questão da objetividade da literatura, nos diz que não podemos apontar literatura como uma categoria una e objetiva, mas sim 
como sendo algo variável e composta ela própria de muitos feixes internos os quais não podem ser ignorados. Para o autor é: "[...] necessário abandonar a ilusão de que a categoria "literatura" é "objetiva", no sentido de ser eterna e imutável. Qualquer coisa pode ser literatura, e qualquer coisa que é considerada literatura inalterável e inquestionavelmente Shakespeare, por exemplo -, pode deixar de sê-lo [...]" (EAGLETON, 1983, p. 11).

Por tudo já arrolado, concluímos que literatura pode representar a vida das pessoas, problemas sociais, conteúdo intelectual e moral que levem a questionar a miséria, a violência, a pobreza e a ausência de políticas eficazes ou praticáveis, embora a função relacionada ao belo também seja um aspecto literário de grande importância. A literatura é uma experimentação dos possíveis, tem a capacidade de movimentar a vida das pessoas, mudar crenças, influenciar personalidades, mas claro, pode não fazer nada dessas coisas e, mesmo assim será ainda literatura, pois como nos diz Jonathan Culler (1999, p.40), “[...] considerar um texto como literatura é indagar sobre a contribuição de suas partes para o efeito do todo, mas não considerar a obra como sendo principalmente destinada a atingir algum fim, tal como nos informar, persuadir"

Em Cidade de Deus (livro e filme) encontramos as características da sociedade brasileira, descreve detalhadamente sobre a violência, os marginalizados e os excluídos. Essas questões têm sido pauta, além do mundo literário e da sétima arte, pauta para produções musicais, programas televisivos. Esses suportes midiáticos tratam do tema violência muitas vezes, classificando-o enquanto testemunhos, documentos ou depoimentos. Sendo assim, não há como ignorar as discussões que tais produções abrem sobre a vida de determinadas pessoas, sobre uma classe social esquecida, excluída, com uma realidade que nem sempre é conhecida pela maioria dos cidadãos brasileiros.

No entanto, Cidade de Deus nos remete a questões de como se deve representar as mazelas da sociedade, o que, no fim das contas, resta da representação, ela é válida? Ela se mantém? Ela alcança seus objetivos? Ela transforma algo da realidade que denuncia? Conforme reportagem de Fernanda Mena (2003), feita com alguns moradores da Cidade de Deus, as obras e, principalmente, o filme causou mais problemas aos moradores, ao invés de contribuir positivamente. De nada serviu expor a vida dos moradores, nenhum beneficio ocorreu na comunidade. Há também queixas de que os relatos tanto do filme como da obra literária não correspondem com a realidade da comunidade. 
As implicações da representação da violência na literatura e no cinema: Cidade de Deus | 209

Lembremo-nos que tanto a literatura e o cinema não necessariamente precisão estar em função de algo, podem até causar algum tipo de reação, tanto positivo como negativo. Pode servir para apenas entreter ou instigar, é possível de até ser um meio para repensar nossa forma convencional de pensar a vida, mas dependerá das várias maneiras que queiramos analisá-la, pois não existe uma única maneira de ler uma obra, assistir um filme. Mas como diz Ítalo Calvino (CALVINO, 2003 p.30 Apud COMPAGNON, 2009, p. 56). "[...] as coisas que a literatura pode procurar e ensinar são pouco numerosas, mas insubstituíveis [...]" (CALVINO, 2003 p.30 Apud COMPAGNON, 2009, p. 56).

A representação dos problemas sociais, da violência, crimes na arte literária e tanto quanto a fílmica, dentre outras, consegue alcançar, algumas vezes, mais pessoas, "incomodar" responsáveis de determinados setores que podem ajudar a mudar situações complexas da sociedade. Com o conhecimento e a discussão mínima necessária o grande público interessado pode tentar mudar algumas ações e práticas na busca de uma sociedade menos severa. Nesse viés, nos diz Antonio Candido (2002 p. 80), que a arte literária interessa como síntese e projeção da experiência humana "[...] e seu texto se forma a partir do contexto" [...]. Portanto, a intrínseca relação entre arte e vida, arte e realidade, mesmo no senso comum, pode ser, muitas vezes, incômoda e também instigante, pois estas como expressão do homem consequentemente refletem o ser sociocultural.

\section{REFERÊNCIAS}

BRITO, João B. de. Literatura no Cinema. São Paulo, UNIMARCO, 2006. CANDIDO, Antônio. Literatura e Sociedade. 8ed. São Paulo: T.A.Queiroz, 2000.

COMPAGNON. Antoine. Literatura para que quê? Trad. de Laura Taddei Brandini. - Belo Horizonte: Editora UFMG, 2009.

CULLER, Jonathan. Teoria Literária: uma introdução. Trad. Sandra Vasconcelos. São Paulo: Beca Produções Culturais Ltda., 1999.

FERREIRA, Aurélio Buarque de Holanda. O Dicionário da Língua Portuguesa. 2aed. Rio de Janeiro: Nova Fronteira, 2008.

DUTRA. ELIANE A. CIDADE DE DEUS - A BANALIZAÇÃO DA VIOLENCIA COMO DISCURSO-. DEFENDIDA EM 12 DE 
210 | Eliane Dutra

SETEMBRO DE 2005. MESTRADO - UNIVERSIDADE FEDERAL DE SANTA CATARINA - UFSC. DEFENDIDA NAS DEPENDÊNCIAS DA UFSC.

EAGLETON, T. Teoria da literatura: uma introdução. Trad. Waltensir Dutra. São Paulo, Martins Fontes, 1983.

ERDELYI. Maria F. Moradores processam autor de Cidade de Deus por dano moral. Disponível em: <https://www.conjur.com.br/2005-jul06/moradores_processam_paulo_lins_dano_moral>. Acesso em $15 / 05 / 2017$.

HOLLANDA. Heloisa B. Disponivel em: <http://www.heloisabuarquedehollanda.com.br/entrevista-a-paulolins/>. Acesso em 10/06/2017.

LINS, P. Sem Medo de Ser. Revista Caros Amigos, maio de 2003.

. Cidade de Deus, 2002, p 308.

. Caminhos entre etnografia, literatura e cinema: entrevista com

Paulo Lins. (A ser publicada em Cadernos de Antropologia e Imagem, PPCIS-UERJ, 2003.) Acesso em 05/01/2018.

PEREIRA, Rogério. Paiol literário. 2012. Disponível em: <http://rascunho.com.br/paulo-lins/>. Acesso em 10/08/2017.

LYRA, Bernadette. Cinema como Meio de Comunicação. Araraquara: Uniara, 14 junho 2002. 2 cassete sonoros.

MENA. FERNANDA. "Cidade de Deus" gera discriminação, dizem favelados. Disponível em <http://www1.folha.uol.com.br/fsp/cotidian/ff1301200315.htm>. Acesso em 10/02/2018.

MORETZ-SOHN, Claudia. Entre câmeras e traficantes (entrevista com F. Meirelles em 06/08/2002). Globo.com. Disponível em: <http://revistaepoca.globo.com/Revista/Epoca/O,EDR511705856,00.html >. Acesso em 05/06/17.

MOTTA, Cláudio. Cidade de Deus reage à violência na tela. Globo Barra, Globo, 28/1/2002.

PEREIRA, Francelino. O Povo do Cinema. Brasília: Agência Nacional do Cinema-ANCINE, 2001.

RIZZO, Ségio. Situando a Retomada. São Paulo: 30 de maio 2003. Entrevista concedida a Renato Márcio Martins de Campos. 1 cassete sonoro.

ROCHA, G. Revisão crítica do cinema brasileiro. Rio de Janeiro: Civilização Brasileira, 1963. 
As implicações da representação da violência na literatura e no cinema:

Cidade de Deus | 211

. Cartas ao mundo: org. Ivana Bentes. São Paulo. Ed. Companhia da Letras, 1997.

ROCHA, Renato O. A dialética da marginalidade em Paulo Lins e Bezerra da Silva. 2014. Artigo publicado em: <http://revista.usp.br/crioula/article/download/74037/92069>. Acesso em 04/06/2017.

SATO, Paula. Quais foram os filmes mais importantes desde a retomada do cinema brasileiro? Disponível em $<$ https://novaescola.org.br/conteudo/1023/quais-foram-os-filmesmais-importantes-desde-a-retomada-do-cinema-brasileiro>. Acesso em $16 / 01 / 2018$.

SCHWARZ, R. Uma aventura artística incomum. Folha de S. Paulo, São Paulo, 07 set.1997. Caderno Mais! Livros. . Sequencias brasileiras. São Paulo: companhia das Letras, 1999. . Os Pobres na Literatura Brasileira. (Org.) São Paulo: Brasiliense, 1983.

TURNER, G. O cinema como prática social. São Paulo: Summus, 1997.

VASCONCELOS, Eduardo H. B. de; MATOS, Renata de F. Do prenúncio ao recomeço: a história do cinema brasileiro no início e no final do século XX. Oficina do Historiador, Porto Alegre, EDIPUCRS, v. 5, n.1, jan./jun. 2012.

VENTURA, Zuenir. Crítica. Folha de São Paulo, dezembro de 2002, Mais!

WARREN, Austin; WELLEK, René. Teoria da literatura e metodologia dos estudos literários. São Paulo: Martins Fontes, 2003.

\section{Bibliografias de sites}

http://anabelamotaribeiro.pt/paulo-lins-a-pretexto-de-cidade-de-deus$\underline{181225}$. Acesso em 10/08/2017.

http://cinemaemcena.cartacapital.com.br/coluna/ler/764/n\%C3\%A3ogosta-de-filme-nacional-entenda-o-cinema-da-retomada. Acesso em $10 / 01 / 2018$

Recebido em: 15/02/2018

Aceito em: 30/03/2018 